\title{
EFFECT OF PATTERNMAKER'S PROFICIENCY ON THE CREATION OF CLOTHING
}

\author{
Kyoungok Kim¹, Tsuyoshi Otani², Masayuki Takatera ${ }^{1 *}$ \\ ${ }^{1}$ Division of Kansei and Fashion Engineering, Institute for Fiber Engineering (IFES), Interdisciplinary Cluster for Cutting Edge Research (ICCER), Shinshu \\ University, 3-15-1 Tokida, Ueda, Nagano, 386-8567, Japan \\ ${ }^{2}$ Faculty of Textile Science and Technology, Shinshu University, 3-15-1 Tokida, Ueda, Nagano, 386-8567, Japan \\ takatera@shinshu-u.ac.jp
}

\begin{abstract}
:
The effect of the patternmaker's proficiency on the creation of clothing was investigated by the observation of the patternmaking process for clothing that satisfies the designer. We asked Japanese and French patternmakers to make a clothing pattern for the same design. The reasons for the differences in resultant clothing patterns and toiles made by the two patternmakers are discussed. Although the patternmaking processes used by the proficient patternmakers were similar, the resultant patterns were different owing to different recognition of the design. In particular, the shape and size of the collar that the designer emphasized in the illustration were different in the resultant patterns. Differences in patternmaking originated from differences in the patternmakers' levels of expertise in terms of education, experience, and proficiency. However, the designer was satisfied with both patterns.
\end{abstract}

\section{Keywords:}

patternmaker, patternmaking, proficiency

\section{Introduction}

An item of clothing is produced by several people including a designer and patternmaker. First, a designer creates a clothing design and presents the design as two-dimensional illustrations. These illustrations show the essentials and goal of the clothing. A patternmaker constructs a representation (a hypothetical internal cognitive symbol that represents real clothing) of the clothing to make a pattern that achieves the designer's goal. Finally, a pattern is constructed and a sewing factory makes the garment using this pattern.

To make a more beautiful and comfortable garment, it is necessary to understand the making procedures of garments especially between designers and patternmakers [1,2]. It is said that a proficient patternmaker can produce a pattern that satisfies the designer more quickly and efficiently with less modifications. However, the gathering and processing of information by patternmakers is not clearly understood. Understanding these procedures is important for efficient work for patternmaker and the management of fashion business as well. Moreover, textile and clothing have intimate relationships. By understanding the garment making process, textile manufacturers will be able to suggest more suitable textiles for making apparel. This will help textile manufacturers for apparel [3]. The performances of experts affect the final results of not only standardized activities but also creative activities. Experts' performances in creative activities have been studied by many researchers. The role of deliberate practice in the acquisition of expert performance was examined by Ericsson et al. [4]. A predictive and explanatory model of career trajectories and landmarks in creative productivity was suggested by Simonton [5]. The effect of the task and proficiency in learning a language was examined by Poulisse et al. taking into account the use of compensatory strategies [6]. Proficiency in creative activities was characterized by Johnson-Laird, who stated that such proficiency involves not only skills that can be obtained by training but also the discovery of new information and knowledge [7]. Kaufman et al [8] investigated writer's creativity by comparing student and expert writers' writings. Oura investigated the proficiency of pianists and practitioners in terms of the cognitive psychology of their creative skills and showed that proficient pianists and Kendo practitioners learn and play by understanding implicit and complicated information [9]. Hardaker and Fozzard [10] described a common framework of bra pattern making along with the variations in individual working methods. However, the effect of the patternmaker's proficiency on the clothing creation is not reported with experiments.

In a previous study [11], we investigated the effects of a patternmaker's proficiency on the patternmaking process and the resultant pattern. We examined the processing of information by a proficient patternmaker (such as attention, recognition, reasoning, decision-making associated with values and preferences, and representation) by watching and asking her questions as she constructed a jacket pattern. Furthermore, we analyzed her level of proficiency as educated, experienced, or proficient, as defined in Table 1. It was found that the proficient patternmaker was able to identify problems and find solutions after taking relevant constraints into consideration and to create a representation that was more in line with the expectations of the designer. The proficient patternmaker was also able to produce clothing that met, or in some aspects surpassed, the designer's expectations. 
Even if the same illustration is given, different patternmakers construct different clothing patterns [12,13]. Designers accept the patterns if they are simply satisfied with the patterns, as nobody has an optimum solution. Therefore, more information is added to the clothing design at the patternmaker's discretion and by the designer's correction as the process progresses [14]. Patternmakers thus affect the clothing creation.

The present paper investigates the effect of the patternmaker's proficiency on the clothing creation by observing the patternmaking process for clothing that satisfies the designer. Reasons for differences between resultant clothing patterns and toiles made by different patternmakers are discussed. Furthermore, we clarify the discretional range of the patternmaker allowed by the designer.

Table 1. Definitions of levels of expertise [11]

\begin{tabular}{|l|c|}
\hline Level & Definition \\
\hline Educated & $\begin{array}{c}\text { Knowledge and skills gained from reading, } \\
\text { formal instruction, and training }\end{array}$ \\
\hline Experienced & $\begin{array}{c}\text { Knowledge and skills gained from work } \\
\text { experience }\end{array}$ \\
\hline Proficient & Creative skills \\
\hline
\end{tabular}

\section{Experimental}

To understand the patternmaker's proficiency, we investigated how the patternmakers make patterns that satisfy the designer taking into account their information processing. We observed the process of patternmaking performed by two patternmakers using the same design. First, we asked a Japanese designer, who has work experience at a French luxury brand, to design a jacket and skirt for women. The season was set as the fall and winter of 2014. The designer provided drawings and measurements. The drawings were an illustration of a model wearing the clothing and a flat drawing of the back as shown in Figure 1. She also selected a fabric for the design. The fabric was tweed with a checked pattern as shown in Figure 2. The model, a French size 38 (bust, $87 \mathrm{~cm}$; waist, $68 \mathrm{~cm}$; hips, $93 \mathrm{~cm}$ ), was also specified.

We selected two patternmakers $\mathrm{P} 1$ and $\mathrm{P} 2$ as expert patternmakers. $\mathrm{P} 1$ is Japanese and has more than 20 years of work experience in Japan and the United States in constructing high-end, ready-to-wear clothing. P2 is French and has more than 13 years of work experience in France in constructing high-end, ready-to-wear clothing. We asked both to make patterns for the same design. P2 had prior experience working with the designer, but $\mathrm{P} 1$ did not.

We provided both patternmakers with the illustration, flat drawing, fabric swatch, and model's size. P1 used apparel CAD software, and $P 2$ used hand drawing. We investigated the information process of the patternmaking by questioning the patternmakers while they worked. The questions were mainly about their recognition processes including finding and solving problems, the reasons for their decisions, and the execution of their plan at each stage of their work. After patternmaking, the patternmakers made a toile with a cotton cloth. They then checked their toile and corrected it. Afterward, the designer checked the toiles. All processes were recorded on video for the confirmation of the operation and answers.

Details of the patternmaker's proficiency in each patternmaking process were investigated in terms of finding and solving problems, decision-making, and reasoning. We judged the level of expertise of each patternmaker in each task of patternmaking as educated, experienced, or proficient as described in Table 1 [11]. We also compared the patterns, toiles, and designer's comments about the toiles.

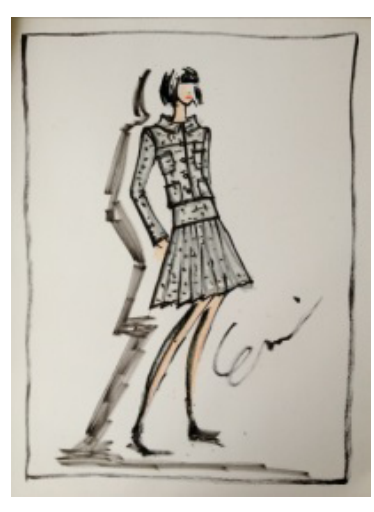

(a)

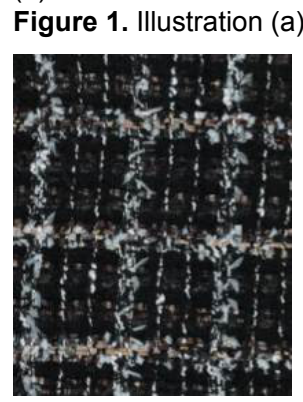

Figure 2. Textile swatch

\section{Results}

We divided the patternmaking process into five steps according to the traditional patternmaking method [15]:

1) constructing a clothing representation,

2) drafting the pattern,

3) fitting a toile to a dress form, followed by the patternmaker checking and modifying the pattern,

4) fitting a toile to a dress form, followed by the designer checking and modifying the pattern, and

5) completing the pattern.

Figures 3 and 4 shows the pictures of $\mathrm{P} 1$ for pattern drafting and fitting a toile to a dress form.

The details of the analysis at each stage of the process and the expertise level of the patternmaker are described in the following section. 


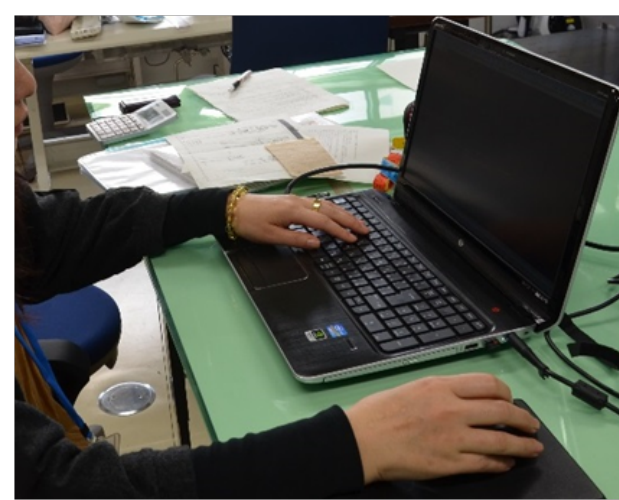

Figure 3. Picture of $\mathrm{P} 1$ for pattern drafting

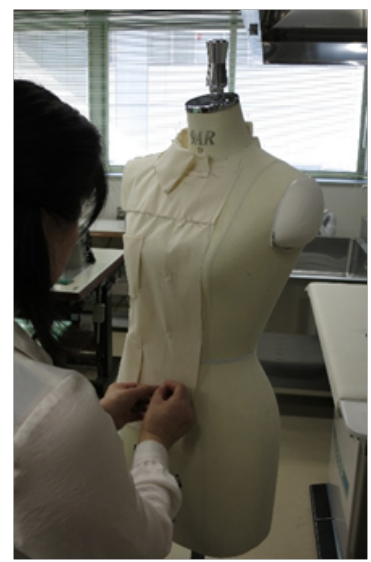

Figure 4. Picture of $\mathrm{P} 1$ for fitting a toile to a dress form

\subsection{Constructing a clothing representation}

In constructing a clothing representation, the general procedures of the two patternmakers were similar. The patternmakers recognized information from the designer's illustration and flat drawing (collectively referred to as the illustrations hereafter). They assumed the wearer's measurements that were not provided. They supplemented information such as the number of bodice pattern pieces, the existence and position of darts and design lines, the number of darts, and attributes (shape, length, and position) of the lines. The patternmakers imagined the clothing and then built a representation of the clothing.

However, there were also procedures that differed between $\mathrm{P} 1$ and $\mathrm{P} 2$. P1 asked the designer about the target consumer and the designer answered that the target consumer is similar to that of a famous luxury brand. Having the illustration and knowing the brand, P1 recognized that the clothing has a classical design. Measurements that were not provided, such as those of the shoulder, neck circumference, and center-back collar height, were assumed from experience after considering the silhouette of the illustrations and a balance with the provided measurements.

Similarly, P2 assumed the unknown measurements from the illustration and the provided measurements taking into account the proportions of the illustration. However, she did not ask about the target consumer.

Both $\mathrm{P} 1$ and $\mathrm{P} 2$ were judged as acting at the experienced level in this task.

\subsection{Drafting the pattern}

In the patternmaking process, the first consideration is the selection of an execution plan for the pattern drafting. Both patternmakers selected a plan using slopers (basic patterns).

P1 used a sloper for a similar design, which she had used previously, for speed and efficiency. P2 similarly used a sloper that she had used in her studies. Because the process was carried out using knowledge from experience, this procedure was judged to be at the experienced level.

Next, the patternmakers decided the measurements of the pattern and drew lines. P1 decided the measurements according to her experience. She used her (learnt) knowledge about the relationship between the number of darts and the representation. P2 also decided a set of measurements using data obtained from education and experience.

The slopers were then modified according to the design illustrations and measurements. In this step, the darts, collar, lapels, shoulder line, and hemline were modified, and the position and size of details (buttons and pockets) were also set.

As the shoulder line, P1 drew a line that she thought was beautiful according to her knowledge, skills, and experience. P1 set and drew the yoke, darts, and pleats taking into account the interval of the fabric pattern in particular. In addition, P1 recognized the possibility of the change in the shape and size of the collar, length of the body, and size and position of the pockets by the designer. For the skirt pleat, $\mathrm{P} 1$ tried to align the fabric pattern when the pleats were folded and sewn. Because P1 had little experience with the checked pattern, she needed more time to decide the interval of pleats than she did to decide other parts. Because she attempted to create beautiful lines according to the design, she was judged to act at the proficient level.

In contrast, P2 determined the position of a line and the shape of a curve and the measurement of each part taking into account the proportions of the clothing in the illustration. She mostly tried to obey the proportions because she believed that they represented the designer's intention. Because she tried to follow the proportions of the design, she was judged to act at the experienced level.

It was thought that the differences in actions of the two patternmakers originated from their different working backgrounds. P1 said that the target age, career, and income affects the clothing silhouette in her experience of the Japanese apparel industry, while P2 said that this is not the case for a French high-end brand. P2 said that a patternmaker working for a French high-end brand focuses more on the design illustration.

Next, the amount of allowance was decided. P1 decided allowance according to the knowledge obtained from learning and experience considering the silhouette. She decided the amount of shrinkage and the allowance for collar folding taking into account the fabric properties. She was judged as acting at the experienced level. 
P2 also decided the allowance according to knowledge obtained from learning and experience. However, she did not consider the fabric properties because she believed that this is the work of sewing factories.

In this step, there was a difference according to the working backgrounds of the patternmakers. P1 said that considering the fabric pattern and sewability is the patternmaker's job in the Japanese apparel industry. P2 said that a sewing factory manufacturing French high-end ready-to-wear also covers the alignment of the fabric pattern and the treatment of sewability.

\subsection{Fitting the pattern to a dress form}

Patternmakers made toiles using thin sheeting fabric to check the pattern by placing it on a dress form. For efficiency, both patternmakers made only half of the jacket.

Both patternmakers first considered the implementation of a plan for pattern fitting. There was a possibility of changing the armhole line when the armhole line in the bodice was not suitable. Thus, they first checked the bodice pattern pieces. They then checked the sleeve. Afterward, they checked the skirt toiles. Both patternmakers were judged to act at the experienced level in making the plans because they used knowledge taken from experience.

Both patternmakers then checked the fitting of the toile on the dress form in relation to the designer's illustrations, considering wrinkles, the shoulder pad, the sleeve, a silhouette of the waistline, details such as the pocket and buttons, and the allowance. In addition to the design details, P1 considered whether the entire silhouette looked beautiful, according to her experience. After checking the pattern in relation to the designer's illustrations, P1 modified the armhole line and collar taking into account the balance and wrinkles. In particular, the size of the pocket was modified by considering the alignment of the fabric pattern. P2 checked the fitting by giving priority to the illustrations. P1 was judged to act at the proficient level, whereas P2 was judged to act at the experienced level because $\mathrm{P} 1$ made what she thought was a beautiful silhouette.

Next, the sewability was examined. Here, P1 set the amount of shrinkage considering the alignment of the fabric pattern, whereas P2 entrusted the factory to address this issue and disregarded the ease of sewing. As mentioned previously in Section 3.2, this difference was due to the different working experiences of the patternmakers. The patternmakers used knowledge taken from the experience and were thus both judged to act at the experienced level.

The patternmakers then confirmed the grain lines according to the knowledge from their education. Thus, they were judged to act at the educated level. After checking and modifying patterns on the dress forms, the patternmakers modified the patterns.

The patterns were now ready for the fitting check by the designer.

\subsection{Toile check by the designer}

The designer checked the toiles taking into account the overall balance including the detail.

Instructions for changes to the toile made by $\mathrm{P} 1$ were as follow:

1) Lower the jacket hemline by $5 \mathrm{~cm}$, as shown in Figure 5 (a).

2) Widen the collar band, as shown in Figure 5 (b).

3) Make the top collar stand up more while keeping the top collar length, as shown in Figure 5 (c), and shorten the end of the top collar by $1 \mathrm{~cm}$, as shown in Figure 5 (d).

4) Lengthen the sleeve by $2-2.5 \mathrm{~cm}$, as shown in Figure 5 (e).

5) Change the sleeve shape so that it is more curved and wider along the sleeve, as shown in the illustrations.

6) Allow the sleeve cap to swell, as shown in Figure 5 (f).

7) Raise the skirt hemline by $1.5 \mathrm{~cm}$ and shorten the yoke by $2.5 \mathrm{~cm}$.

Instructions for changes to the toile made by $\mathrm{P} 2$ were as follows:

1) Narrow the yoke of the skirt, while keeping the length of the whole skirt.

2) Narrow the width of the neckband and collar band.

Although the yoke length followed that in the illustration, the designer asked the patternmakers to modify it because she judged that a shorter yoke is better than a longer yoke. This means that the designer's representation was changed.

The designer did not communicate with P1 directly and the authors delivered the pictures for the modification of the toile and directions to P1 as shown in Figure 5. In contrast, P2 received instruction from the designer directly.

The designer wanted to check the modified toile made by P1 according to the new pattern but did not wish to check the modified toile made by $\mathrm{P} 2$.

\subsection{Modifying the pattern according to the designer's directions}

After receiving the designer's comments, the patternmakers confirmed the designer's requests. In accordance with the designer's comments, P1 modified patterns taking into consideration the balance. During this process, P1 took into account the modification of the pattern according to the designer's comments while considering the entire balance of the pattern, to keep a shape that she thought was good. She also attempted to catch the designer's intention for the design. The modified pattern and toile are shown in Figures 6 and 8. The modification was judged to be at the experienced level. 
The toile modified by P1 was shown to the designer and the designer wanted the collar to stand up more.

P2 modified her patterns according to the designer's instruction. The modified pattern and toile are shown in
Figures 7 and 8 . The procedures were judged to be at the experienced level.

We summarized the differences of patternmaking process between patternmakers as shown in Table 2 .

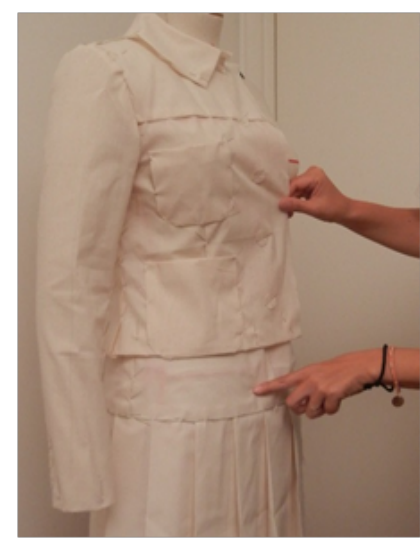

(a)

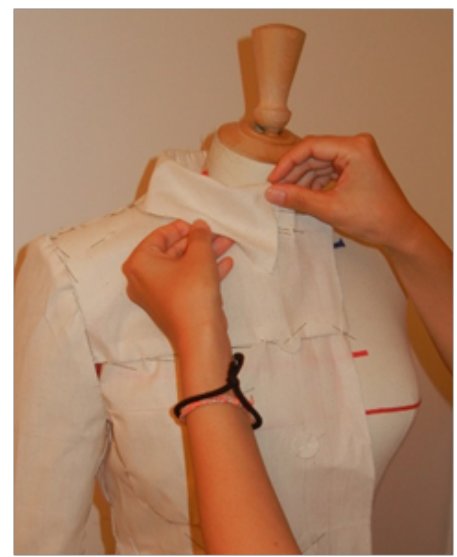

(d)

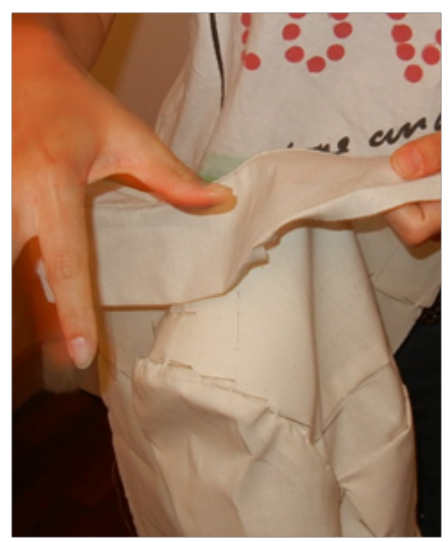

(b)

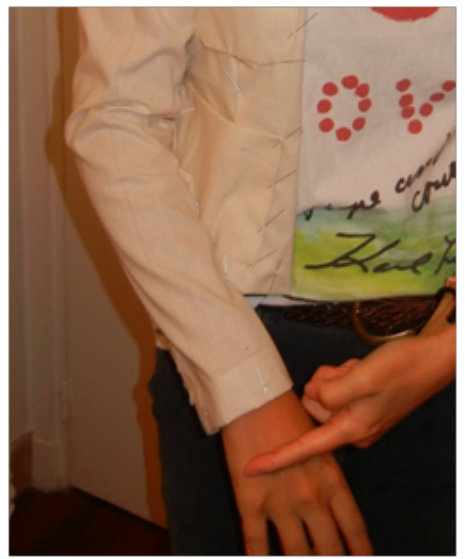

(e)

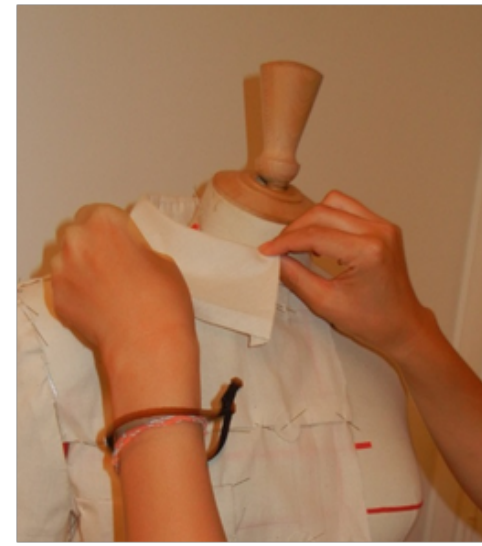

(c)

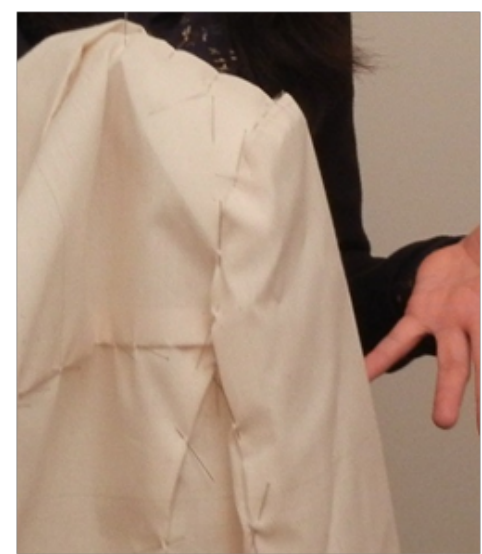

(f)

Figure 5. Modifications of the toile by P1 requested by the designer

Table 2. Differences of patternmaking process between patternmakers

\begin{tabular}{|c|c|c|}
\hline $\begin{array}{c}\text { Patternmaker } \\
\text { Patternmaking process }\end{array}$ & P1 & P2 \\
\hline \multirow[b]{2}{*}{ Constructing a clothing representation } & Needed information of target consumer & $\begin{array}{c}\text { Not needed information of target } \\
\text { consumer }\end{array}$ \\
\hline & $\begin{array}{l}\text { Taking into account the silhouette of } \\
\text { the illustrations and a balance with the } \\
\text { provided measurements }\end{array}$ & $\begin{array}{l}\text { Taking into account the proportions of } \\
\text { the illustration }\end{array}$ \\
\hline \multirow{3}{*}{ Pattern drafting } & $\begin{array}{l}\text { Drew a line that she thought was } \\
\text { beautiful according to her knowledge, } \\
\text { skills, and experience }\end{array}$ & $\begin{array}{c}\text { Drew a line taking into account the } \\
\text { proportions of the clothing in the } \\
\text { illustration }\end{array}$ \\
\hline & $\begin{array}{l}\text { Attempted to create beautiful lines } \\
\text { according to the design }\end{array}$ & $\begin{array}{l}\text { Tried to follow the proportions of the } \\
\text { design }\end{array}$ \\
\hline & Taking into account fabric properties & Not taking into account fabric properties \\
\hline \multirow{2}{*}{ Pattern drafting } & $\begin{array}{l}\text { Considered whether the entire } \\
\text { silhouette looked beautiful }\end{array}$ & $\begin{array}{l}\text { Checked the fitting by giving priority to } \\
\text { the illustrations }\end{array}$ \\
\hline & Taking into account sewability & Not taking into account sewability \\
\hline
\end{tabular}


Table 3 Measurements of pattern parts (unit: $\mathrm{cm}$ )

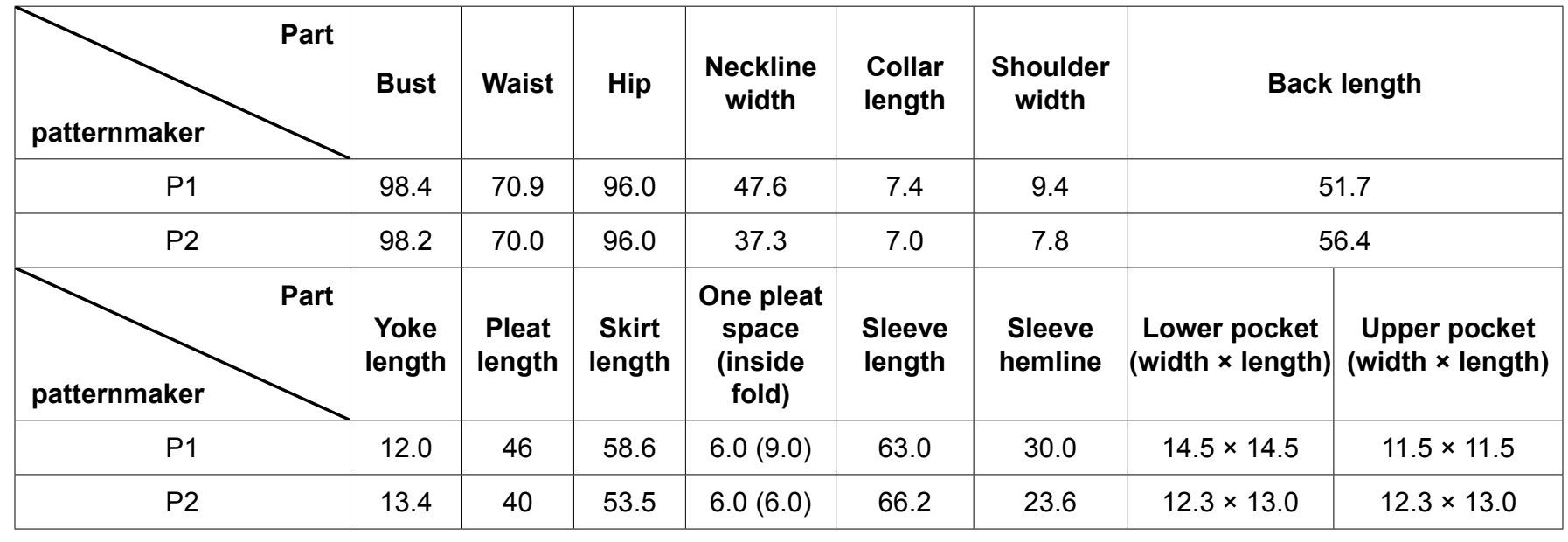
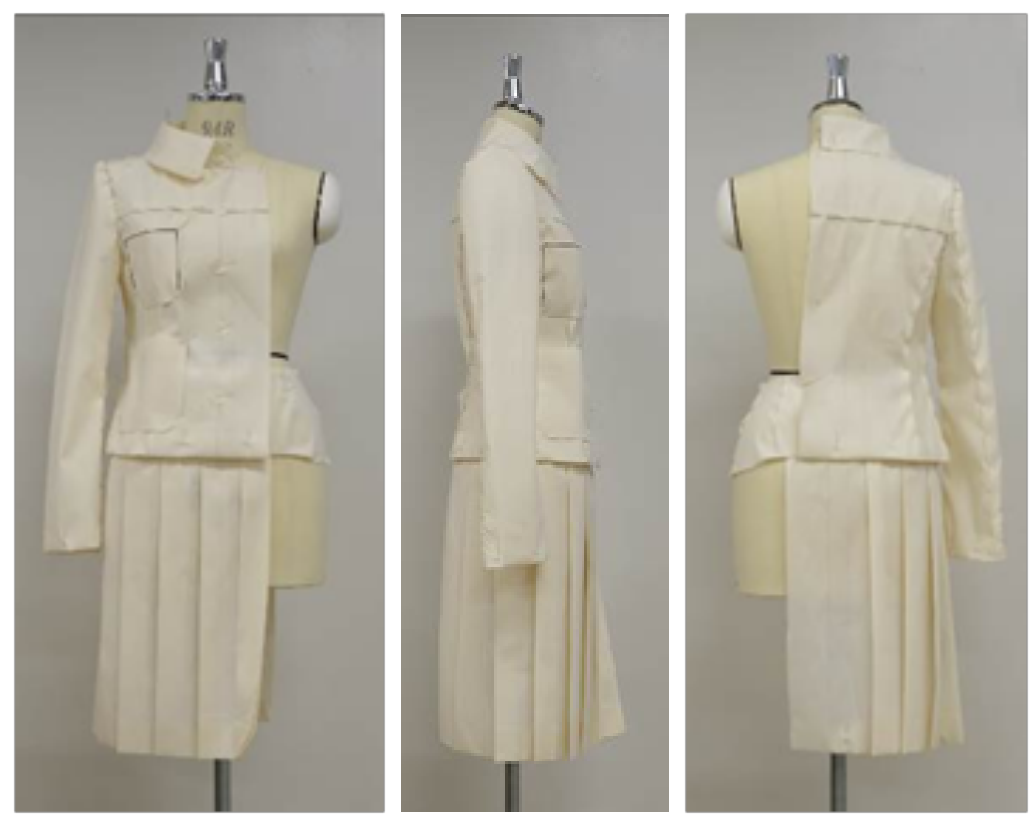

Figure 6. Toile modified by P1 on a dress form after the designer's feedback
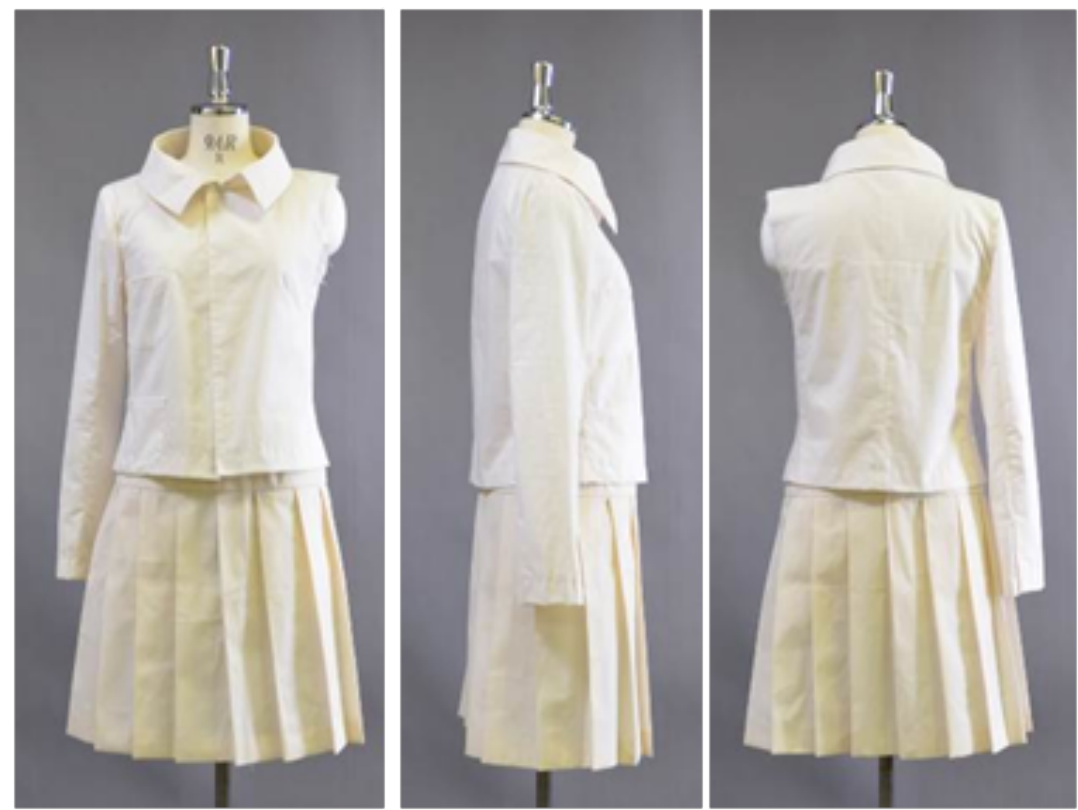

Figure 7. Toile modified by P2 on a dress form after the designer's feedback 

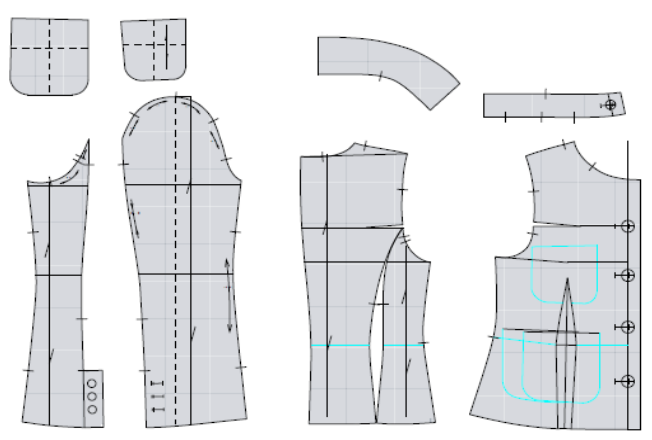

(a) Jacket pattern of P1

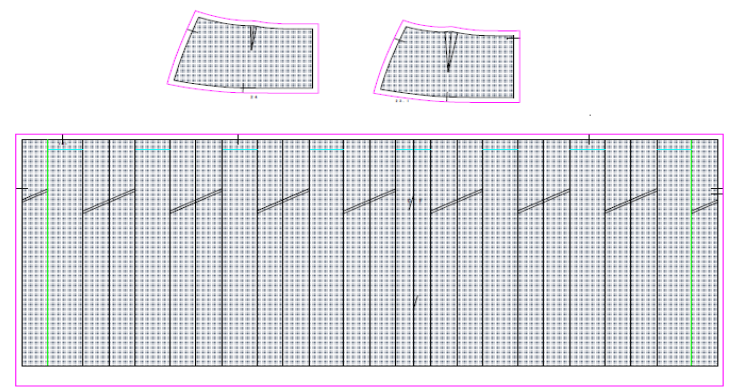

(c) Skirt pattern of P1

Figure 8. Modified patterns after the designer's feedback

\section{Discussion}

\subsection{Effect of patternmaker's proficiency on clothing creation}

Table 3 gives the measurements of each pattern part. The measurements of the bust, waist, and hip, which were provided by the designer, were very similar in comparison of the patterns made by $\mathrm{P} 1$ and $\mathrm{P} 2$; differences were less than $1 \mathrm{~cm}$. However, as shown in Figure 8, curves of the waist, the ratio of the three bodice parts, and the collar shape were different. Thus, the resultant patterns were different. Moreover, the length of the neckline and the shape and size of the collar were different, although the width of the collar was similar. The skirt length of $\mathrm{P} 1$ was longer than that of $\mathrm{P} 2$. The sleeve hemline of $\mathrm{P} 1$ was longer than that of $\mathrm{P} 2$. $\mathrm{P} 1$ made two different pocket patterns, whereas $\mathrm{P} 2$ made one pocket pattern. The width and number of skirt pleats were the same, although P1 made different measurements of the outside and inside of the pleats.

Although the designer asked both $\mathrm{P} 1$ and $\mathrm{P} 2$ to modify the collar, the revised shapes still differed. This was because the patternmakers recognized different representations from the illustrations.

As a result of the different patterns, the appearances of the toiles also differed. In particular, the collar shape and waist constriction were different as shown in Figures 6 and 7 . Furthermore, the spreading of the skirt differed.
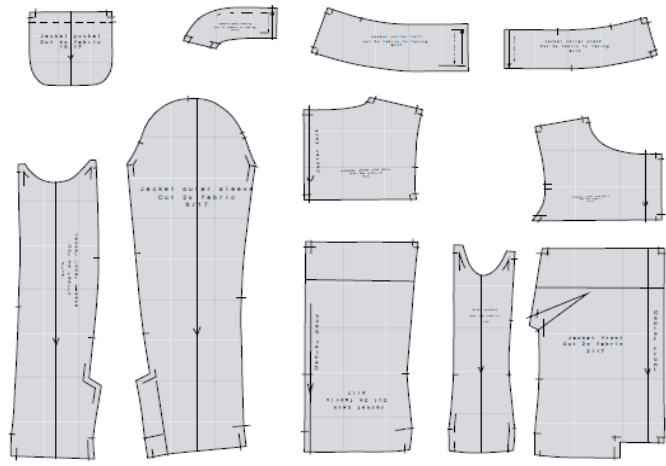

(b) Jacket pattern of P2
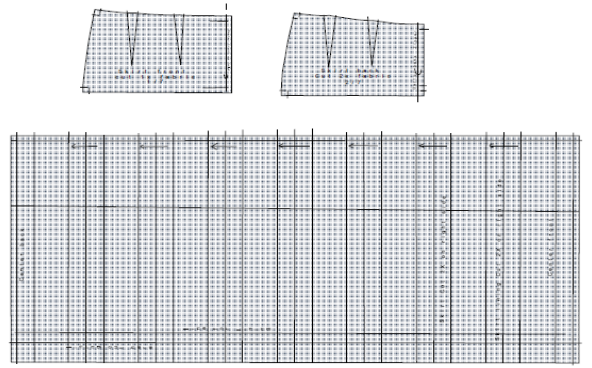

(d) Skirt pattern of P2
Although the resultant toiles had different shape, measurements, and silhouette, the designer was satisfied with both. Both toiles were satisfactory solutions to the illustrations. The patternmaker's discretion was thus demonstrated, revealing that a fashion designer's creation partially relies on the patternmaker's proficiency.

Differences in patternmaking originated from differences in the patternmakers' expertise levels in terms of their experience and proficiency.

\subsection{Effect of communication and the manufacturing system}

It was thought that the reasons for the differences in patternmaking were due to different backgrounds and communication methods relating to the work experiences of the patternmakers.

First, the work experience affected the information process. Because a patternmaker working at a Japanese apparel company considers the target consumer, P1 wanted to recognize the target consumer of the design, whereas P2 did not. Thus, in addition to the illustrations, the target consumer affected the recognition of the design. The differences between toiles were because of the different interpretations of the design. Because a patternmaker working at a French high-end brand concentrates more on the designer's intention according to an illustration, P2 attempted to recognize the designer's intention and thus recognized the collar and sleeve design more precisely than $\mathrm{P} 1$. 
The communication method also affected the recognition of designer's representation. Because P1 did not communicate with the designer directly, she did not confirmed designer's intention clearly. Thus, P1 mentioned many points that she would change after the toile was checked by the designer because those will be changed. It was thought that direct communication is more effective in delivering the designer's intention to the patternmaker. In contrast, indirect communication would require more details.

Another difference was in the set of measurements of the garments that were not provided. Both patternmakers set such measurements according to the illustrations. However, P1 set the measurements by also considering the current trend and the target consumer, whereas P2 set them taking into account the illustration mostly.

Furthermore, $\mathrm{P} 1$ made more particular inquiries than $\mathrm{P} 2$ to the designer in the first step. As a result, the designer gave more instructions to P1 than to P2. However, P2 achieved a closer match with the designer's illustrations. P2 had experience working with the designer at the high-end French brand, and P2 and the designer may thus have had mutual tacit consent.

Finally, in addition to considering the silhouette and details, P1 took into account the alignment of the fabric pattern for sewing, whereas P2 did not. A patternmaker should consider the alignment of the fabric pattern in the clothing pattern for Japanese and American sewing factories. However, factories used by French high-end brands cover this themselves. This difference was related not to the proficiency of the patternmaking itself but to the difference in manufacturing systems.

\section{Conclusions}

The effect of the patternmaker's proficiency on the creation of clothing was investigated by the observation of the patternmaking process for clothing that satisfies the designer. The information gathering and processing of the patternmakers became clear. Although the patternmaking processes of proficient patternmakers were similar, the resultant patterns were different. The reasons for the differences between resultant clothing patterns and toiles made by different patternmakers were clarified.

Although the resultant toiles had different shape, measurements, and silhouette, the designer was satisfied with both toiles. The patternmaker's discretion was thus demonstrated. It was found that a fashion designer's creation partly depends on a patternmaker's proficiency. This is evidenced by the patternmakers adding information to the clothing design as the process progressed [14].

Differences in patternmaking were due to differences in the patternmaker's level of expertise in terms of experience and proficiency.

In addition, P1 made her pattern considering the illustrations and her own information about the target consumer. P2 focused on capturing the designer's intension by matching the proportions of the illustration. This difference in approach is thought to be because of the different working experiences of the patternmakers and the different manufacturing systems in Japan and Europe.

Although the results of the study do not fully explain the patternmaker's proficiency, they explain the effect of the patternmaker's proficiency on clothing creation.

\section{ACKNOWLEDGMENTS}

This work was supported by the Japan Society for the Promotion of Science KAKENHI grant number JP24220012.

\section{References}

[1] LaBat, K. L., and Sokolowski, S. L. (1999). A three-stage design process applied to an industry-university textile product design project. Clothing and Textiles Research Journal, 17(1), 11-20.

[2] McKinney, E. C., Bye, E., \& LaBat, K. (2012). Building patternmaking theory: a case study of published patternmaking practices for pants. International Journal of Fashion Design, Technology and Education, 5(3), 153167.

[3] Rissanen, Timo. "Types of fashion design and patternmaking practice." Nordes 2 (2007). University of Arts, Crafts and Design, Stockholm, Sweden May 27, 2007 - May 30

[4] Ericsson K. A, Krampe Ralf Th. and Tesch-Romer C. (1993) The Role of Deliberate Practice in the Acquisition of Expert Performance, Psychological Review, 100(3), 363406.

[5] Dean Keith Simonton; Creative Productivity. (1997) A Predictive and Explanatory Model of Career Trajectories and Landmarks, Psychological Review, 104(1), 66.

[6] Poulisse N and Schils E (1989). The Influence of Task- and Proficiency-related Factors on the Use of Compensatory Strategies: A Quantitative Analysis, Language Learning, 39(1), 15-46.

[7] Johnson-Laird P. The Computer and the Mind: An Introduction to Cognitive Science, Harvard University Press, Cambridge, MA, 1989.

[8] Kaufman, James C., Claudia A. Gentile, and John Baer. (2005) Gifted Child Quarterly Do gifted student writers and creative writing experts rate creativity the same way?." 49(3) 260-265.

[9] Oura Y, Sōzō-teki ginō ryōiki ni okeru jukutatsu-ka no ninchi shinrigakutekikenkyū [Cognitive Psychology Studies of Proficiency of Skills in the Creative Area], Kazamashobo, Tokyo [in Japanese], 2000.

[10] C.H.M. Hardaker, G.J.W. Fozzard. (1997) "The bra design process - a study of professional practice”, International Journal of Clothing Science and Technology, Vol. 9 Iss: 4, pp.311 - 325

[11] Kim KO, Takatera M and Otani T. Effect of a Patternmaker's Proficiency on Clothing Production, 2014.11.20-21, Global Fashion Conference 2014, Belgium, Ghent. 
[12] Kim KO, Miyatake K, Sano K, Takatera M and Otani T. (2013) Comparison of high-end tailored jackets for readyto-wear produced in Italy and Japan, International Journal of Affective Engineering, 13(1), 35-41.

[13] Kim KO, Miyatake K, Sano K, Takatera M and Otani T. (2013) Research on Jacket Patterns and Specifications of Ready-to-wear for High-end in Italy and Japan, International Journal of Affective Engineering, 13(1), 27-33.
[14] Otani T, Kim KO, Takahashi M, Inui S, Morikawa H and Takatera M. (2014) International Presence and Fashion Business in Japan: To Advocate the Construction of Fashion Engineering, Journal of Japan Society of Kansei Engineering, 12(4) 1-40.

[15] Frings GS, Fashion: From Concept to Consumer, 9th Edition, Prentice Hall, New Jersey, 2007. 